Research Article

\title{
Experimental Investigations on Electrical Charge of Precracked Rock Specimens under Uniaxial Compression
}

\author{
Feng He $\mathbb{D}$, ${ }^{1}$ Zhenwei Wang $\left(\mathbb{D},{ }^{2}\right.$ Yangfeng Zhao $\mathbb{D D}^{1}$ Gaofeng Song $\mathbb{D}^{2},{ }^{2}$ and Bowen Liu $\mathbb{D}^{2}$ \\ ${ }^{1}$ Department of Mechanics \& Engineering, Liaoning Technical University, Fuxin 123000, China \\ ${ }^{2}$ School of Civil Engineering, North China University of Technology, Beijing 100144, China \\ Correspondence should be addressed to Gaofeng Song; song.gaofeng@ncut.edu.cn
}

Received 18 September 2020; Revised 12 October 2020; Accepted 19 October 2020; Published 31 October 2020

Academic Editor: Guangchao Zhang

Copyright $\odot 2020$ Feng He et al. This is an open access article distributed under the Creative Commons Attribution License, which permits unrestricted use, distribution, and reproduction in any medium, provided the original work is properly cited.

The electrical charge characteristic of rock materials under compression is an important index for predicting the development of rock fractures and the failure of engineering structures. However, the charge behaviours of a preexisting rock sample have not been studied in depth. In this study, sandstone samples with a single fabricated precrack at different angles of inclination are prepared. The uniaxial compression tests are performed to study the charge behaviours associated with the initiation and propagation of secondary cracks, the mechanical properties, and the progressive failure of stressed rock samples. An improved analytical model based on the maximum tensile stress failure theory for brittle materials is also proposed for determining the crack growth paths of the single precrack rock samples under uniaxial compression. The friction factors of crack surfaces are computed. The results show that the step functions on the curves of charge accumulation over time correspond to the fluctuation of stress, indicating the initiation of microcracks. The sample with a crack inclination angle of $\pi / 4$ shows the largest amount of both the first charge and the total accumulation. The analytical model shows a positive relationship between the crack face friction factors and the charge accumulation. The analytical solution of the crack development angles shows good agreement with the experimental results. This work may provide reference for the similar studies regarding the correlation of charging behaviours to the compressed rock materials.

\section{Introduction}

The microcracks in rock mass have a major impact on the overall mechanical properties and the stability of underground rock structures [1]. Researchers have performed extensive studies in the field of cracked rock samples using experimental, theoretical, and numerical approaches. Zhao developed a microcrack sliding model of a rock sample subjected to uniaxial compression for analysing the propagation of microcracks and the development of anisotropy $[2,3]$. Yang and Cheng performed triaxial compression tests on rock samples with fabricated precracks to study the failure characteristics at different confining pressures $[4,5]$. They concluded that the deformation characteristics of the secondary microcracks transfer from the elastic state to the perfectly plastic state with the increase of confining pressures. Yue et al. compared the failure mechanisms of rocks containing running cracks and precracks [6]. On the other hand, the initiation of microcracks throughout the failure process of rocks is typically associated with the occurrence of electric charge, which becomes an important indicator for the rock failure evolution. Volarovich performed a series of experimental tests to study the charging behaviours of rock samples including the granite, gneiss, and gangue $[7,8]$. Ogawa observed both positive and negative charges generated from the secondary crack surfaces [9]. Guo et al. believes that the stress concentration around the crack tips leads to the contraction of atom and increase in electron energy [10]. The electron then flees and therefore causes the charge separation. Kilkeev observed a positive relationship between the compression stress and the generated charges from the uniaxial compression tests on cylinder samples [11]. Sun et al. obtained the charge quantity on the fracture surfaces from the magnetic field intensity during the growth 
of rock fractures [12]. Wu et al. revealed the charge characteristics on the granite surfaces by measuring the microcurrent [13]. Zhu et al. observed the electric energy around the area of crack tips during microcrack initiation [14]. Kuksenko et al. performed the loading tests on marbles and observed a significant increase of generated charge at the beginning of compression; it then gradually diminishes [15]. Wang et al. conducted compression tests on coal samples and observed negative charges at the tensile areas around crack tip and positive charges at compression areas $[16,17]$. The potential difference between the surfaces of coal and crack was generated. Yang studied the development of electric potential at the friction interface between coal and rock [18]. Ding et al. obtained the progressive development of electric charges at different stress stages [19]. Pan utilized the charge sensors to investigate the charging characteristics of the coal, granite, and sandstone $[20,21]$. Zhao et al. studied the instantaneous impulse signals of coal samples under uniaxial and triaxial loading conditions [22-25]. The influence of loading rate, confining pressures, and pore methane pressures on the charge signals was included in their work.

This paper attempts to perform the uniaxial compression tests on sandstone rock samples with a single fabricated precrack at different inclination angles. The goal is to study the charge accumulation of the single precrack samples throughout the loading test and its correlation with the compression strength, the precrack inclination angle, crack growth angle (path), and the crack face friction factor. An analytical model based on the maximum tensile stress failure theory is also proposed for determining the crack growth and is compared with the experimental results. This work may provide reference for the stability analysis of the underground openings including entries [26-28] and longwall panels [29, 30].

\section{Electric Charging Behaviours of Stressed Sandstone Samples}

2.1. Sample Preparation and Experimental Procedure. Standard cylinder rock samples with a height of $100 \mathrm{~mm}$ and a diameter of $50 \mathrm{~mm}$ were taken from the sandstone roof above the coal bed in Wulong mine, Fuxin. A rock cutting machine was used to create the single opening-mode precrack on each of the rock samples. The precrack has an aperture of $2 \mathrm{~mm}$ and a depth of $20 \mathrm{~mm}$ at different inclination angles of $0, \pi / 6, \pi / 4, \pi / 3$, and $\pi / 2$. Note that the inclination angle is measured from the crack surface to the loading direction. For instance, an inclination angle of 0 represents a vertical crack parallel to the axis of the cylinder sample, while $\pi / 2$ represents a horizontal crack perpendicular to the axis (see Figure 1). The fabricated cracks were then filled with a mixture of gypsum and water with a proportion of $1: 1$ by weight (Figure $1(\mathrm{~b})$ ). The fill materials were fully mixed before placing to the crack void on the samples. The precracked samples with fill materials were cured at room temperature for $24 \mathrm{~h}$ before being subjected to the compression test for studying the charging characteristics associated with the failure process. In this research, a total of 15 precracked sandstone samples were prepared and classified into 5 groups, corresponding to the $5 \mathrm{crack}$ inclination angles, respectively. Each group includes 3 samples. Figure 1 plots a final view of the samples with fabricated precracks before the compression test. The sample with the inclination angle of 0 was labelled as Sample 1 , and $\pi / 6, \pi / 4$, $\pi / 3$, and $\pi / 2$ were labelled as Samples $2-5$, respectively.

The precracked sandstone samples were subjected to the uniaxial compression test with a consideration of the progressive development of electric charge. Figure 2 shows the experimental test system used in this research, which included an MTS loading machine run in displacement control mode (Figure 2(a)), a charging signal shielding device (Figure 2(b)), and a signal collection system (Figure 2(c)). A constant displacement rate of $0.001 \mathrm{~mm} / \mathrm{s}$ was applied to the loading plate. All the tests were performed at the same displacement rate. Figure 3 provides a schematic of the placement of rock samples and measurement system in the experimental test. The charging signal acquisition system consists of the charge sensors, A/D converters, and a data acquisition unit. The charge sensor has a measurement range of $\pm 1.526 \times 10^{-5} \sim 5 \times 10^{-11} \mathrm{C}$. Its sensitivity is given as $A_{\mathrm{CQ}}=1 \times 10^{11} \mathrm{~V} / \mathrm{C}$. The sensor probes were placed on the shielding device at $5-10 \mathrm{~mm}$ away from the front, left, and right surfaces of the rock sample for detecting the charging development throughout the loading process. The stressstrain curves, failure characteristics of the sample, and the progressive crack propagation were also captured by a camera and were compared with the detected charging behaviours.

2.2. Instantaneous Electric Charge. Figure 4 plots the compression stress and instantaneous charge quantity as a function of time. The stress-strain curve is given as the black solid curve, and the instantaneous charge is shown as pink. The first major charge of the sample under compression is marked by a blue circle. The occurrence of major charges indicates the initiation and propagation of new cracks. For Sample 1, the first charge quantity is about $8 \mathrm{pC}$ at a stress level of $7.5 \mathrm{M} \cdot \mathrm{Pa}$ when the loading test continues approximately for a period of $250 \mathrm{~s}$. Two other major charges less than $10 \mathrm{pC}$ are also observed as the vertical stress increases. These major charges correspond to a sudden change in stress on the black curve. The instantaneous charge quantity increases significantly to about $50 \mathrm{pC}$ shortly after the peak strength is reached at $34.01 \mathrm{M} \cdot \mathrm{Pa}$. Similar tendency is observed for Samples 2-5; i.e., the first major charges are approximately around $10 \mathrm{pC}$ and the maximum charges are $50 \mathrm{pC}$. It is also found that the maximum charges do not necessarily occur after the peak strength (see Sample 3). However, it may still be inferred that the tremendous increase in the charge quality only occurs in the vicinity of the region of sample failures. The failure characteristics of the stressed samples after the compression test are also provided in Figure 4. The secondary crack first initiates from the edge of the preexisting crack and then develops to the top and bottom of the cylinder samples. The coalescence of the secondary cracks leads to the final failure of the samples. Of 


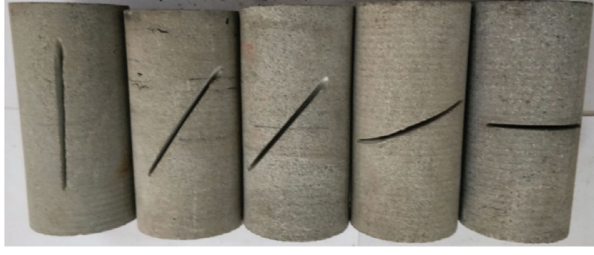

(a)

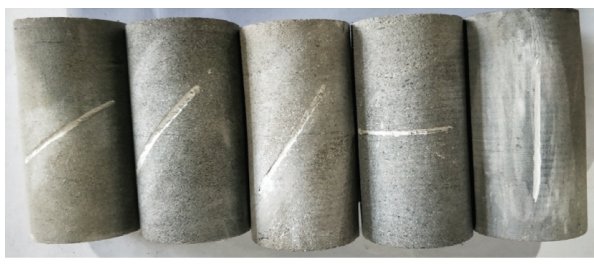

(b)

Figure 1: A final view of the precracked sandstone samples with different inclination angles of precracks: (a) before and (b) after the gypsum fill.

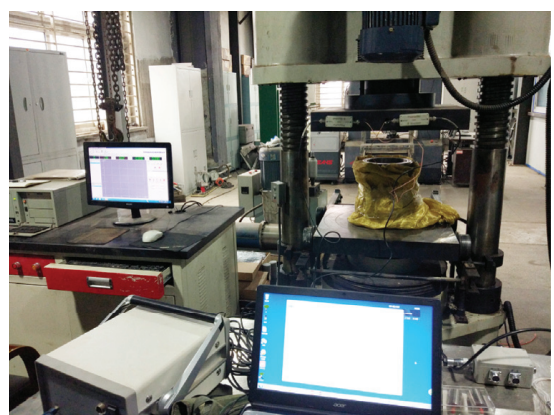

(a)

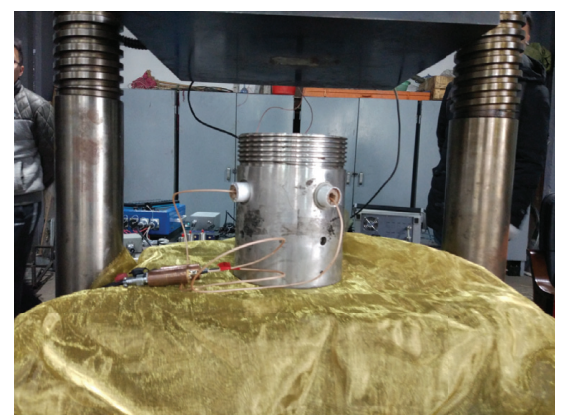

(b)

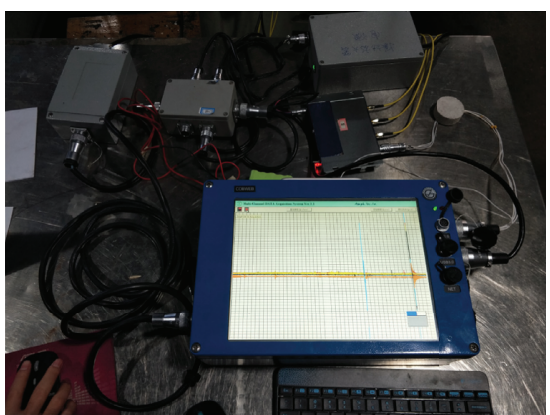

(c)

FIGURE 2: The uniaxial loading system: (a) the loading machine and measuring system; (b) signal shielding device; (c) data collection system.

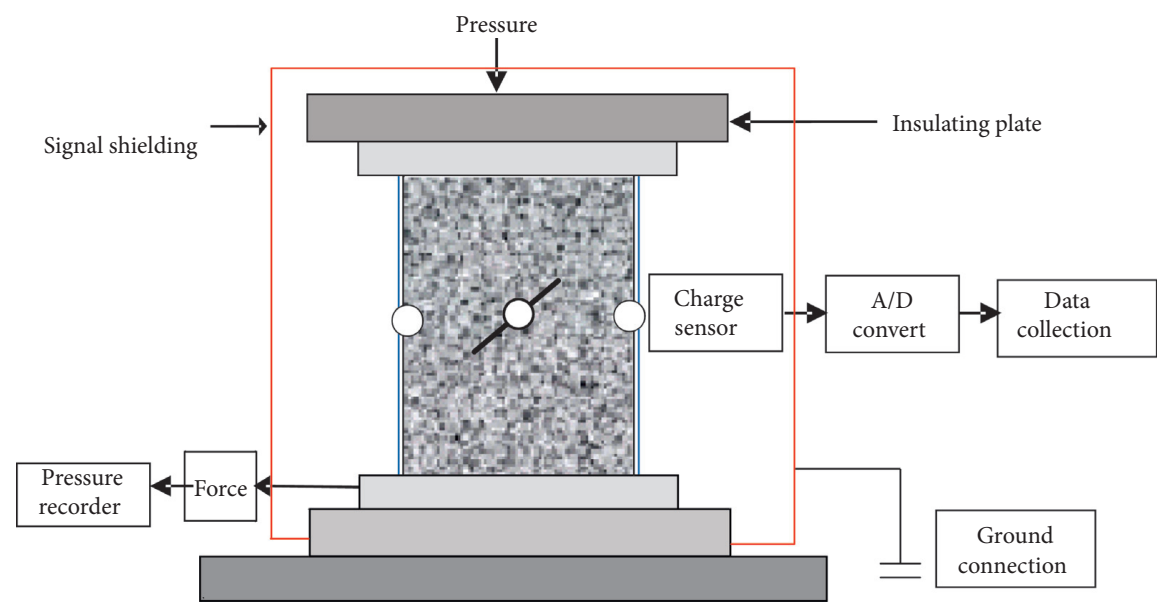

Figure 3: A schematic of the experimental test system.

those, Samples 1 and 5 with a vertical/horizontal crack show tensile failure, while Samples 2, 3, and 4 with inclined cracks show both tensile and shear sliding failures.

The mechanical properties and charge parameters for Samples 1-5 can be found in Table 1. The peak strength of the samples increases gradually with the precrack inclination angle. The quantity of the first charge is around $10 \mathrm{pC}$ for all the samples, which typically occurs after 250-280s of the loading test for most of the samples. Sample 1 shows the earliest first charge, while Sample 5 shows the latest. The stress level at first charge also increases with the precrack inclination angle. It is worth noting that the peak strength is about 4-7 times the stress at the first charge. Other major electric charges occur when the stress approaches the peak strength, and the quantities increase dramatically as compared with the first charge. The maximum charges are mostly observed after the stress drops from the peak strength. The maximum charges for the five samples reach the level of approximately $50 \mathrm{pC}$, indicating that the inclination angle of precrack has little to none influence on the level of maximum charge. In this study, the secondary crack growth angle is defined as an acute angle measured from the preexisting crack surface to the secondary crack surface in the counterclockwise direction. The main angle of the secondary crack growth is also given in Table 1. The crack growth angles are approximately $50-90^{\circ}$. 
TABle 1: Mechanical and electric charging parameters for precracked sandstone samples.

\begin{tabular}{lccccccc}
\hline Sample & $\begin{array}{c}\text { Precrack inclination } \\
\text { angle }\end{array}$ & $\begin{array}{c}\text { Peak strength } \\
(\mathrm{MPa})\end{array}$ & $\begin{array}{c}\text { First charge } \\
(\mathrm{pC})\end{array}$ & $\begin{array}{c}\text { Time at first } \\
\text { charge }(\mathrm{s})\end{array}$ & $\begin{array}{c}\text { Stress at first } \\
\text { charge }(\mathrm{MPa})\end{array}$ & $\begin{array}{c}\text { Maximum } \\
\text { charge }(\mathrm{pC})\end{array}$ & $\begin{array}{c}\text { Secondary crack } \\
\text { growth angle }\end{array}$ \\
\hline Sample 1 & 0 & 34.01 & 8 & 253 & 7.5 & 50 & $-70^{\circ}$ \\
Sample 2 & $\pi / 6$ & 37.35 & 12 & 263 & 7.8 & 52 & $-62^{\circ}$ \\
Sample 3 & $\pi / 4$ & 38.05 & 11 & 272 & 7.6 & 48 & $-50^{\circ}$ \\
Sample 4 & $\pi / 3$ & 44.56 & 6 & 277 & 10.3 & 51 & $-52^{\circ}$ \\
Sample 5 & $\pi / 2$ & 44.88 & 11 & 283 & 12.32 & 49 & $-90^{\circ}$ \\
\hline
\end{tabular}

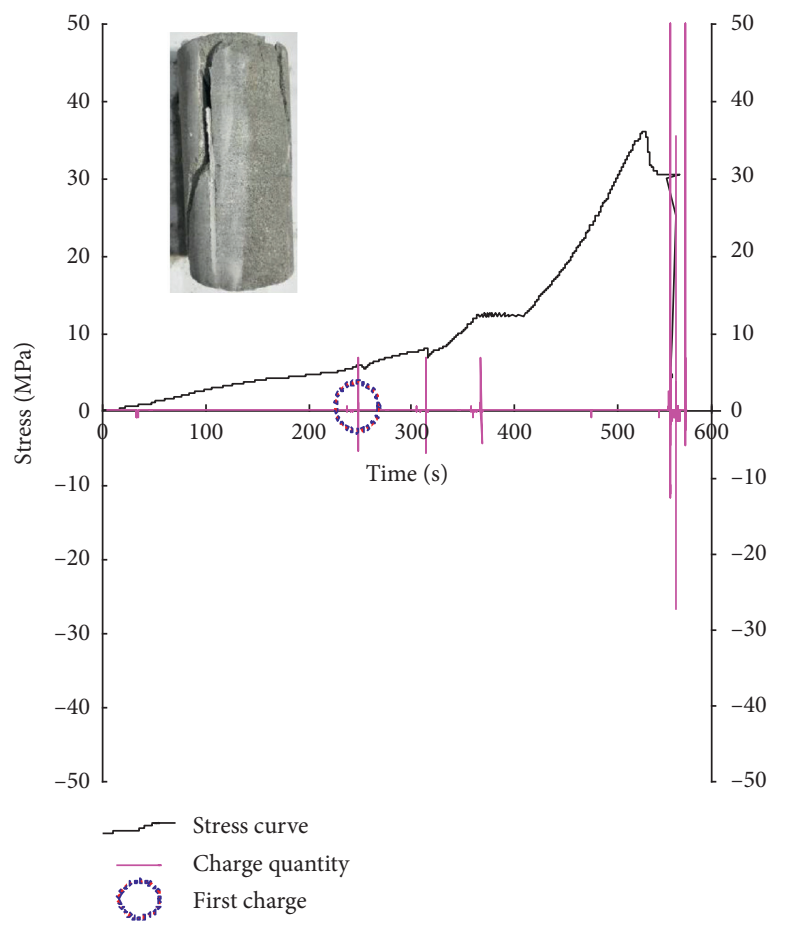

(a)

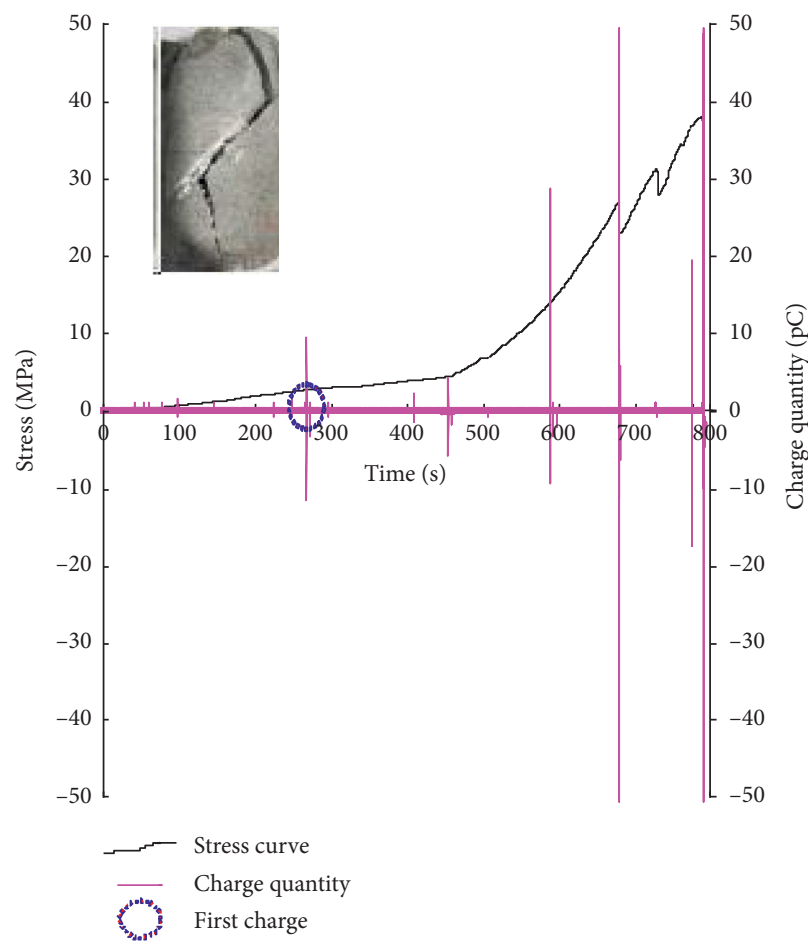

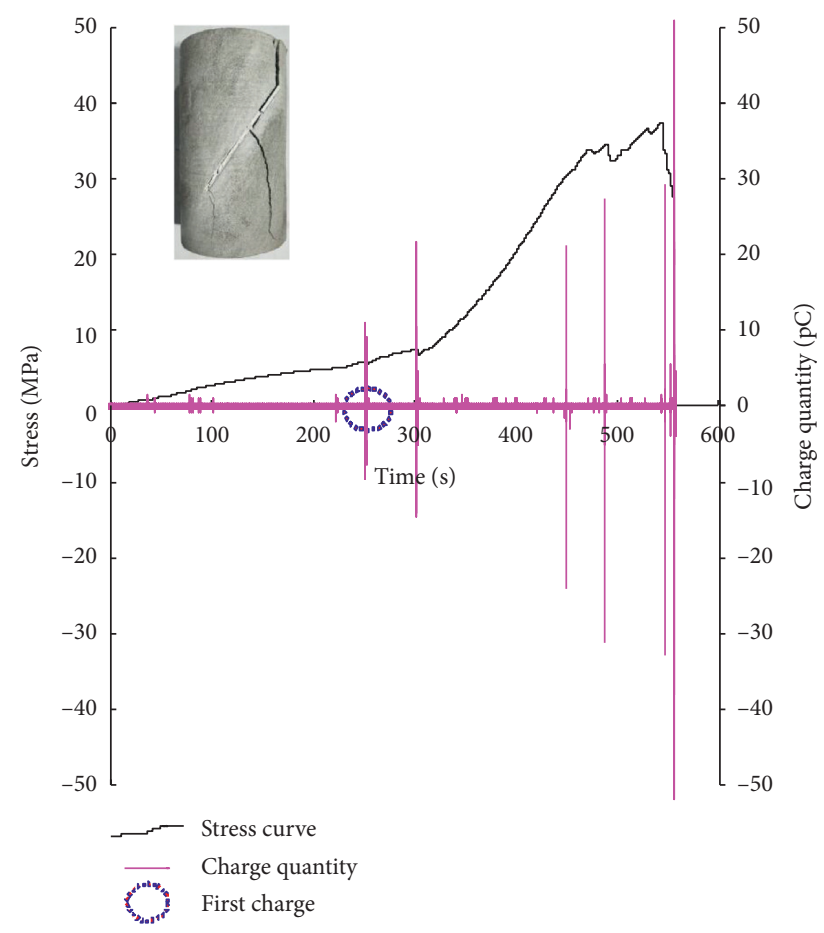

(b)

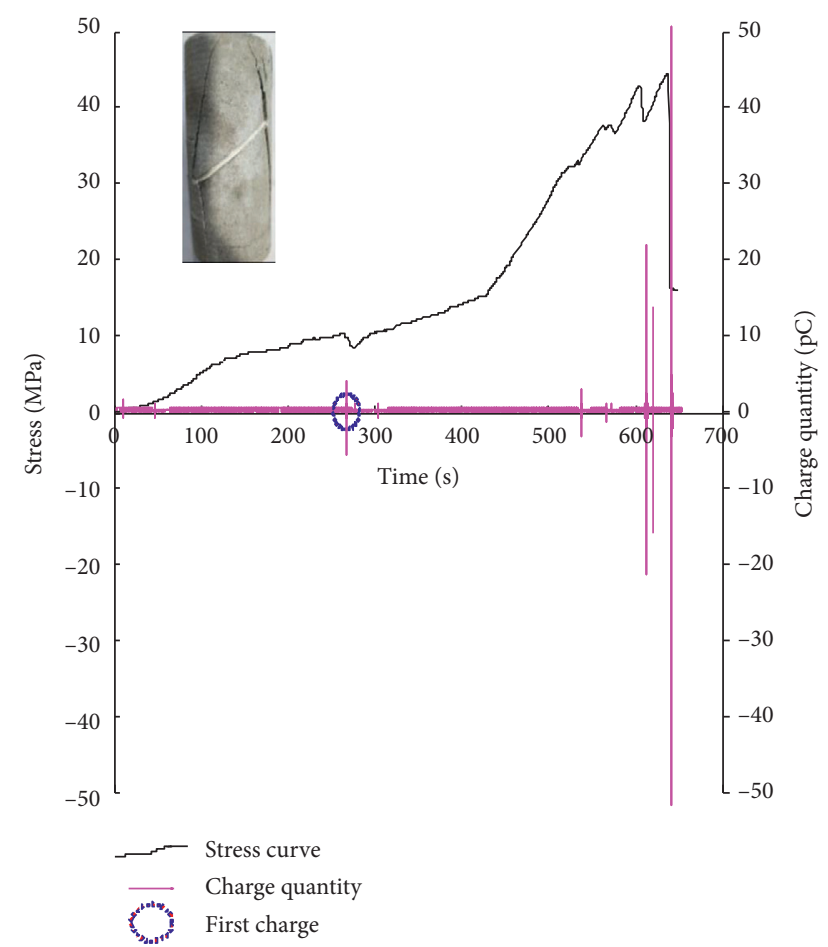

(d)

Figure 4: Continued. 


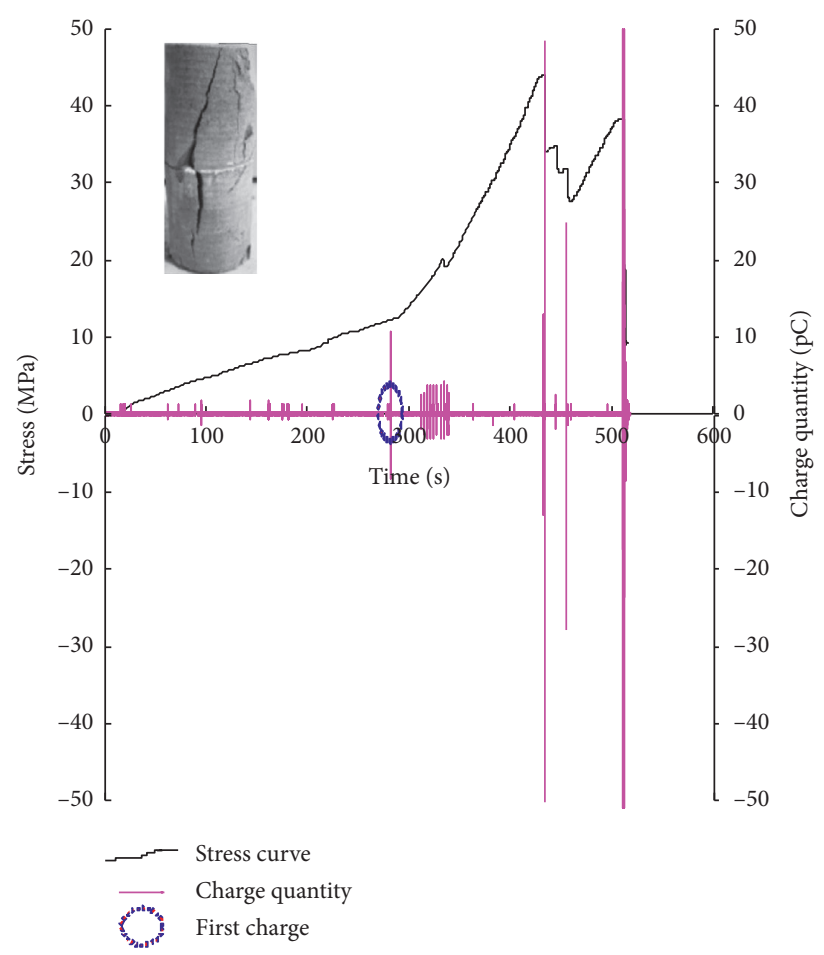

(e)

FIGURE 4: Variation of stress and instantaneous charge quantity as a function of time and failure characteristics of precracked samples with different inclination angles. (a) Sample 1. (b) Sample 2. (c) Sample 3. (d) Sample 4. (e) Sample 5.

2.3. Charge Accumulation. The development of the electric charge accumulation for the precracked samples is given in Figure 5. The charge accumulation for different samples increases in a step function, which may indicate the initiation of the secondary cracks. The first major increase in the electric charge accumulation (or the first charge accumulation) is marked with a blue circle in Figure 5. The first charge accumulation occurs at approximately 250-280 s after the start of the loading test, corresponding to the first instantaneous charge for the five rock samples. A sudden and sharp increase in the charge accumulation is observed at the end of the curve, corresponding to the failure of the rock materials. The final charge accumulation is referred to as the amount of the total received electric charge when the loading test ceases. The final charge accumulation for Samples 1, 2 , and 3 is found at $3.04 \times 10^{4}, 3.28 \times 10^{4}$ and $4.09 \times 10^{4} \mathrm{pC}$, respectively, which are significantly larger than $0.97 \times 10^{4}$ and $1.17 \times 10^{4} \mathrm{pC}$ for Samples 4 and 5 (see Table 2). Sample 3 with an inclination angle of $\pi / 4$ shows the largest first charge accumulation and the final charge accumulation.

\section{Analytic Solution for Predicting Crack Growth}

3.1. Model Development. An analytic model is also developed in this paper for determining the stress state and the crack development of a rock sample with a preexisting crack under the uniaxial compression. Figure 6 shows a rock sample with a single inclined crack under the uniaxial pressure of $p$. The length of the precrack is $2 \mathrm{c}$. The crack angle is $\beta$ measured from the crack surface to loading direction. The secondary crack growth angle $\theta$ is measured from the preexisting crack surface to the secondary crack surface, with counter-clockwise notation assumed positive (see Figure 6(a)). An element of the rock sample containing a small crack is extracted and given in Figure 6(b). The origin of coordinates is set at middle of crack, with the $x$ axis is directed along the crack surface and the $y$ axis is directed perpendicular to the crack surface.

The stress state of the element is given as

$$
\begin{aligned}
\sigma_{x} & =\sigma \cos ^{2} \beta, \\
\sigma_{y} & =\sigma \sin ^{2} \beta, \\
\tau_{x y} & =\frac{1}{2} \sigma \sin (2 \beta),
\end{aligned}
$$

where $\sigma$ is the maximum principal stress; $\sigma_{x}$ is the tangential stress along the crack surface; $\sigma_{y}$ is the normal stress perpendicular to the crack surface; $\tau_{x y}$ is the shear stress; $f$ is the friction factor between the upper and lower crack surfaces. The actual shear stress $\tau_{e}$ along the crack surface can be written as

$$
\tau_{e}=\tau_{x y}-f \sigma_{y}=\frac{1}{2} \sigma \sin (2 \beta)-f \sigma \sin ^{2} \beta
$$

3.2. Crack Surface Friction Factor. Considering the friction between the surfaces of internal flaws or precracks, 


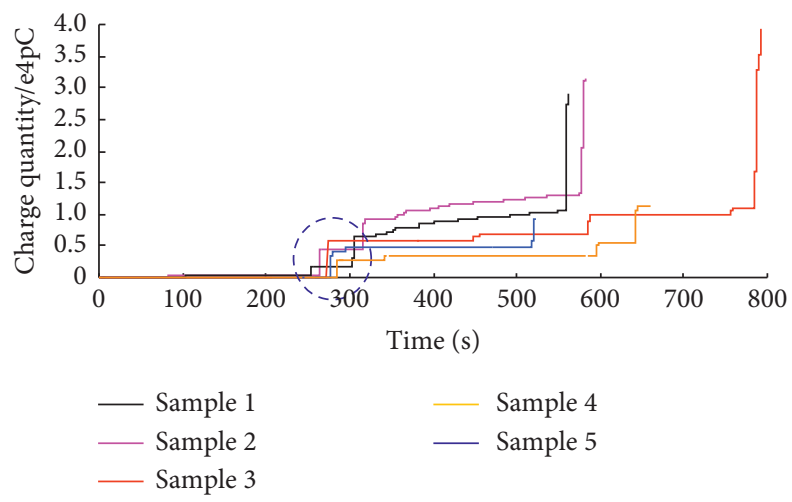

FIGURE 5: Variation of charge accumulation for precracked samples.

TABLE 2: Charge accumulation for precracked sandstone samples.

\begin{tabular}{lccccc}
\hline Sample & $\begin{array}{c}\text { Precrack } \\
\text { inclination angle }\end{array}$ & $\begin{array}{c}\text { Charge accumulation at first } \\
\text { step }\left(10^{4} \mathrm{pC}\right)\end{array}$ & $\begin{array}{c}\text { Time at first } \\
\text { step }(\mathrm{s})\end{array}$ & $\begin{array}{c}\text { Final charge } \\
\text { accumulation }\left(10^{4} \mathrm{pC}\right)\end{array}$ & $\begin{array}{c}\text { Time at total charge accumulation } \\
(\mathrm{s})\end{array}$ \\
\hline Sample 1 & 0 & 0.21 & 253 & 3.04 & 561 \\
Sample 2 & $\pi / 6$ & 0.46 & 263 & 3.28 & 581 \\
Sample 3 & $\pi / 4$ & 0.57 & 272 & 4.09 & 792 \\
Sample 4 & $\pi / 3$ & 0.29 & 277 & 0.97 & 662 \\
Sample 5 & $\pi / 2$ & 0.42 & 283 & 1.17 & 523 \\
\hline
\end{tabular}

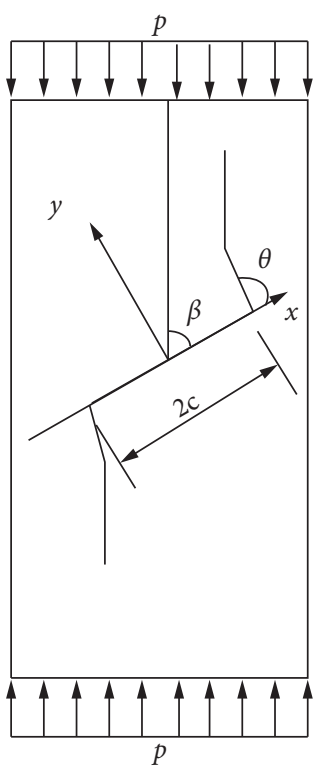

(a)

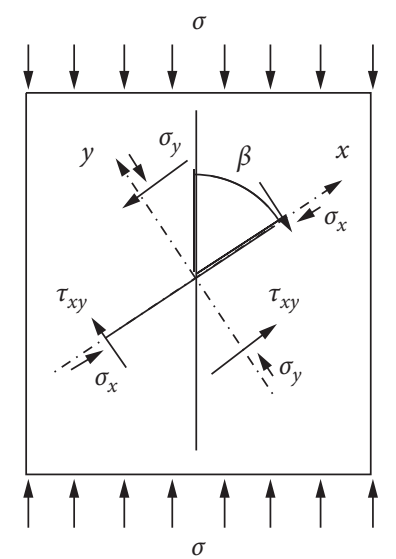

(b)

FIgURE 6: A schematic of the analytic model for calculating the crack growth and crack stress state. (a) A precrack rock sample under uniaxial compression; (b) Stress state of the precrack.

Medintock and Walsh proposed an improved Griffith fracture criterion given in equation (3), by assuming that the secondary crack grows along the maximum tensile stress [31]:

$$
\sigma_{1}=\frac{-4 \sigma_{t}}{\left(1-\left(\sigma_{3} / \sigma_{1}\right)\right) \sqrt{f^{2}+1}-f\left(1+\left(\sigma_{3} / \sigma_{1}\right)\right)},
$$


where $\sigma_{1}$ and $\sigma_{3}$ are axial and lateral stresses; $\sigma_{t}$ is the uniaxial tensile strength. Let $\sigma_{3}=0$, and equation (3) is reduced to

$$
\sigma_{c}=\frac{-4 \sigma_{t}}{\sqrt{f^{2}+1}-f},
$$

where $\sigma_{c}$ is the uniaxial compression strength. Equation (4) shows the relationship between the uniaxial compression and tensile strength of brittle materials (rock and coal mass) with preexisting internal flaws. The friction factor of crack surface can be calculated by substituting the peak strength and the tensile stress at the first charge obtained from the above experimental test. The results are given in Table 3 . The friction factors for Samples 1, 2, and 3 are significantly larger than those for Samples 4 and 5, showing similar tendency with the total charge accumulation listed in Table 2. Sample 3 has the largest friction factor and the final charge accumulation, while Samples 4 and 5 show the least. This indicates that the friction between the crack surfaces has an impact on the amount of generated charge.

3.3. Direction of Crack Growth. The stress intensity factor is used in this study to describe the stress state and stress singularity around the crack tip. The stress intensity factors for Modes I and II prefractures can be calculated as

$$
\left\{\begin{array}{l}
K_{\mathrm{I}}=\sigma_{y} \sqrt{\pi c}=\sigma \sin ^{2} \beta \sqrt{\pi c}, \\
K_{\mathrm{II}}=\tau_{e} \sqrt{\pi c}=\left((\sigma / 2) \sin 2 \beta-f \sigma \sin ^{2} \beta\right) \sqrt{\pi c},
\end{array}\right.
$$

where $K_{\mathrm{I}}$ and $K_{\mathrm{II}}$ are the stress intensity factors for Mode I and Mode II fractures. The precrack in Figure 6(a) is a mixed mode fracture. According to the maximum tangential stress criterion, the secondary crack growth angle is defined as

$$
\theta=\frac{360}{\pi} \arctan \left(\left(1-\sqrt{\frac{\left.1+8\left(K_{\mathrm{II}} / K_{\mathrm{I}}\right)^{2}\right)}{4\left(K_{\mathrm{II}} / K_{\mathrm{I}}\right)}}\right)=\frac{360}{\pi} \arctan \left(\frac{1}{4 \cot \beta-4 f}\left(1-\sqrt{1+\frac{8(\cos \beta-f \sin \beta)^{2}}{\sin ^{2} \beta}}\right)\right),\right.
$$

where $\theta$ is the secondary crack growth angle developing along the direction of maximum tangential stress component. Substituting the friction factors into equation (6), the crack growth angles for different samples are computed and given in Table 3 . The crack growth angles are approximately 50-90 for Samples 1 to 5. The calculated angles from the analytical model can be compared with those observed from the laboratory test results shown in Table 2. Good agreement between the experimental and theoretical results is found.

In fact, equation (6) defines the relationship between the secondary crack development angle $\theta$ and the preexisting crack inclination angle $\beta$. The relationship between $\theta$ and $\beta$ can be studied by substituting $f, K_{\mathrm{I}}$ and $K_{\mathrm{II}}$ into equation (6), where the friction factor is selected as between 0 and 0.5 , and $K_{\mathrm{I}}$ and $K_{\mathrm{II}}$ are calculated from equation (5). A parametric analysis is performed by manually changing the inclination angle of the preexisting crack $\beta$ from 0 to $\pi / 6$. The development of secondary crack growth angle with relation to the precrack inclination angle is plotted in Figure 7. The crack growth angle $\theta$ approaches $-70^{\circ}$ when the precrack inclination angle $\beta$ is 0 . Generally, the absolute value of the crack growth angle reduces with the increase of the crack inclination angle. As the friction factor increases, the crack growth angle becomes positive, indicating that the secondary crack propagates in the counter-clock direction with respect to the surface of the precrack.

\section{Summary and Discussion}

In this work, the charging behaviour and development of secondary cracks for a single precrack rock samples under the uniaxial compression are studied using the experimental and analytical approaches. The sandstone rock samples with a single fabricated crack at different angles of inclination are prepared. Uniaxial compression tests on the precracked samples are performed to obtain the charging characteristics, the mechanical behaviours, and the secondary crack development. An improved analytical model is also proposed for determining the crack development based on the maximum tensile stress failure theory. Important findings are given below.

The instantaneous charge and the charge accumulation over time for different samples are obtained and compared with the stress curves. The sudden increase in the instantaneous charge corresponds to the fluctuations on the stress curves, indicating the initiation and propagation of the secondary cracks. The occurrence of the first charge is about 253-283 s from the start of the compression test for all the inclined samples. The peak strength of the samples is about 4-5 times the stress at the first charge. Samples with precrack angle of $\pi / 4$ show the largest first and total charge accumulations. An analytical solution of the crack development angle is obtained from the analytical model. The crack face 
TABLE 3: Crack surface friction factors and secondary crack growth angles for different samples.

\begin{tabular}{lcccc}
\hline Sample & Precrack inclination angle & Final charge accumulation $\left(10^{4} \mathrm{pC}\right)$ & Crack surface friction factor & Secondary crack growth angle \\
\hline Sample 1 & 0 & 3.04 & 0.13 & $-70^{\circ}$ \\
Sample 2 & $\pi / 6$ & 3.28 & 0.18 & $-59^{\circ}$ \\
Sample 3 & $\pi / 4$ & 4.09 & 0.23 & $-49^{\circ}$ \\
Sample 4 & $\pi / 3$ & 0.97 & 0.088 & $-52^{\circ}$ \\
Sample 5 & $\pi / 2$ & 1.17 & 0.094 & $-90^{\circ}$ \\
\hline
\end{tabular}

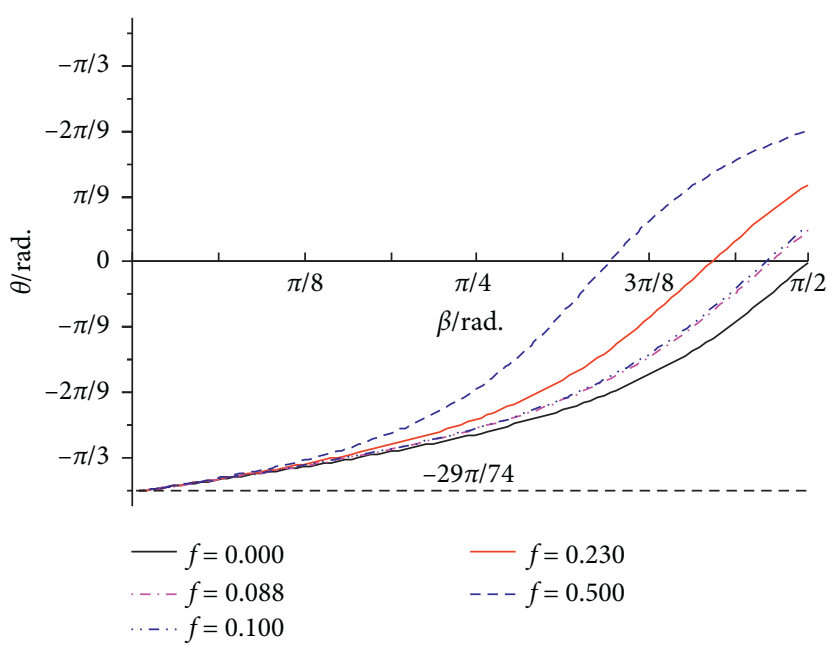

FIGURE 7: Relation between the crack growth angle and precrack inclination angle for samples with different crack surface friction factors.

friction factors are calculated, and they show a positive relationship with the charge accumulation. The $\pi / 4$ precrack sample shows the largest friction factor on crack surfaces. The crack development angles are similar for both the experimental and analytical results.

\section{Data Availability}

The data used to support the findings of this study are included within the article.

\section{Conflicts of Interest}

The authors declare that they have no conflicts of interest.

\section{Acknowledgments}

This research was supported by General Programs of the National Natural Science Foundation of China (Grant nos. 51774184, 51774884, and 52004010), Excellent Research Team Fund in North China University of Technology (Grant no. 107051360019XN134/017), and Scientific Research Fund in North China University of Technology (Grant no. 110051360002).

\section{References}

[1] H. Lee and S. Jeon, "An experimental and numerical study of fracture coalescence in pre-cracked specimens under uniaxial compression," International Journal of Solids and Structures, vol. 48, no. 6, pp. 979-999, 2011.
[2] S. L. Zhao, G. Zhang, M. X. Li et al., "Rock microcrack's dominant direction and the anisotropy," Journal of Wuhan University of Technology, vol. 37, no. 5, pp. 57-63, 2015.

[3] S. L. Zhao, Study on Thermal-water-Force Coupling of Brittle Rock Based on Crack Model, pp. 12-21, Wuhan University of Technology, Wuhan, Hubei, China, 2017.

[4] S. Q. Yang, S. Wen, and L. Q. Li, "Experimental study on deformation and strength properties of coarse marble with discontinuous pre-existing cracks under different confining pressures," Chinese Journal of Rock Mechanics and Engineering, vol. 27, no. 8, pp. 1572-1587, 2007.

[5] L. Cheng, S. Q. Yang, and X. R. Liu, "Experimental and numerical investigation on crack expansion of sandstone containing flaws," Journal of Mining \& Safety Engineering, vol. 29, no. 5, pp. 719-724, 2012.

[6] Z. W. Yue, Y. Song, X. Wang et al., "Interaction between a preexisting crack defect with different angles and a running crack," Explosion and Shock Waves, vol. 37, no. 1, pp. 162-168, 2017.

[7] M. P. Volarovich and E. I. Parkhomenko, "Piezoelectric effect of rocks,” DANSSSR, vol. 99, no. 2, pp. 239-240, 1954.

[8] M. P. Volarovich and E. I. Parkhomenko, "Piezoelectric effect of rocks," Izv . Academy of Sciences of the USSR. Ser Geophiz, vol. 100, no. 2, pp. 215-222, 1955.

[9] T. Ogawa, K. Oike, and T. Miura, "Electromagnetic radiations from rocks," Journal of Geophysical Research, vol. 90, no. D4, pp. 6245-6249, 1985.

[10] Z. Q. Guo, J. H. You, G. Li et al., "The model of compression atoms and electron emission of rock fracture," Acta Geophysica Sinica, vol. 32, no. 2, pp. 173-177, 1989.

[11] R. S. Kilkeev, Electric Field of Rock under Force Load, pp. 31-34, Beijing Seismological Press, Beijing, China, 1993. 
[12] Z. J. Sun, L. H. Wang, and H. Gao, "Electromagnetic emission and light radiation during fracture of rock samples," Journal of Geophysics, vol. 29, no. 5, pp. 491-495, 1986.

[13] X. P. Wu, X. J. Shi, and Z. Q. Guo, "Study of the electrification of granite samples under compression," Acta Geophysica Sinica, vol. 33, no. 2, pp. 208-211, 1990.

[14] Y. Q. Zhu, X. L. Luo, Z. Q. Guo et al., "A study of mechanism on electromagnetic emission associated with rock fracture," Acta Geophysica Sinica, vol. 34, no. 5, pp. 594-601, 1991.

[15] V. S. Kuksenko and K. F. Makhmudov, "Mechanically-induced electrical effects in natural dielectrics," Technical Physics Letters, vol. 23, no. 2, pp. 126-127, 1997.

[16] E. Y. Wang, X. Q. He, Z. T. Liu et al., "Study on electromagnetic emission characteristics of loaded rock and its application," Chinese Journal of Rock Mechanics and Engineering, vol. 21, no. 10, pp. 1473-1477, 2002.

[17] E. Y. Wang, X. F. Liu, X. Q. He et al., "Acoustic emission and electromagnetic radiation synchronized monitoring technology and early-warning application for coal and rock dynamic disasters," Journal of China University of Mining and Technology, vol. 47, no. 5, pp. 942-948, 2018.

[18] Y. L. Yang, Z. H. Li, E. Y. Wang et al., "Experiment study on surface potential characteristics and rules during coal or rock friction process," Journal of China Coal Society, vol. 38, no. 2, pp. 215-220, 2013.

[19] X. Ding, X. C. Xiao, and X. F. Lu, "Investigation on charge signal time-frequency domain characteristics in coal failure process and noise reduction," Journal of China Coal Society, vol. 43, no. 3, pp. 657-666, 2018.

[20] Z. Tang, Y. S. Pan, G. Z. Li et al., "The analysis of induced charge of electric friction in coal-rock," Progress in Geophysics, vol. 28, no. 2, pp. 975-979, 2013.

[21] Z. Tang, Y. S. Pan, Z. H. Li et al., "Charge induction mechanism in the process of fracture of coal-rock," Chinese Journal of Geotechnical Engineering, vol. 35, no. 6, pp. 1156-1160, 2013.

[22] Y. F. Zhao, Y. S. Pan, G. Z. Li et al., "Detection of charge induced signal in the process of rock deformation and fracture," Journal of Disaster Prevention and Mitigation Engineering, vol. 30, no. 3, pp. 252-256, 2010.

[23] Y. F. Zhao, Y. S. Pan, and W. J. Su, "Study on charge change of granite samples under uniaxial compression," Natural Science, vol. 28, no. 2, pp. 221-224, 2009.

[24] Y. F. Zhao, L. Q. Liu, Y. S. Pan et al., "Experiment study on micro seismic charge induction, self-potential and acoustic emission during fracture process of rocks," Chinese Journal of Rock Mechanics and Engineering, vol. 36, no. 1, pp. 107-123, 2017.

[25] Y. F. Zhao, L. Q. Liu, and Y. Zhang, "Microshock and chargeinduced signal variation of brittle rock specimens with threepoint bending," Journal of Experimental Mechanics, vol. 33, no. 6, pp. 929-937, 2018.

[26] G. C. Zhang, Z. J. Wen, S. J. Liang et al., "Ground response of a gob-side entry in a longwall panel extracting $17 \mathrm{~m}$-thick coal seam: a case study," Rock Mechanics and Rock Engineering, vol. 53, no. 2, pp. 497-516, 2019.

[27] G. C. Tan, F. L. He, H. G. Jia et al., "Analysis of gateroad stability in relation to yield pillar size: a case study," Rock Mechanics and Rock Engineering, vol. 50, no. 5, pp. 1-16, 2017.

[28] G. F. Song and S. L. Yang, "Probability and reliability analysis of pillar stability in South Africa," International Journal of Mining and Mineral Engineering, vol. 28, no. 4, pp. 715-719, 2018.
[29] D.-Z. Kong, Z.-B. Cheng, and S.-S. Zheng, "Study on the failure mechanism and stability control measures in a largecutting-height coal mining face with a deep-buried seam," Bulletin of Engineering Geology and the Environment, vol. 78, no. 8, pp. 6143-6157, 2019.

[30] Z.-B. Cheng, L.-H. Li, and Y.-N. Zhang, "Laboratory investigation of the mechanical properties of coal-rock combined body," Bulletin of Engineering Geology and the Environment, vol. 79, no. 4, pp. 1947-1958, 2020.

[31] L. Brian, Fracture of Brittle Solids, pp. 20-32, Beijing Higher Education Press, Beijing, China, 2010. 